\title{
Dynamics of Agricultural Productivity and Poverty in Pakistan
}

\section{S.M. Turab Hussain \& Mohammad Ishfaq}

\begin{abstract}
This paper addresses two topics which essentially compliment each other. The first is the empirical investigation of the relationship between aggregate agricultural productivity and poverty in Pakistan through the course of time. The second is the estimation of the central inputs or determinants of agricultural production, again on an aggregate level and through time. The main empirical findings of this research suggest that increases in agricultural productivity have alleviated poverty in Pakistan but not to the extent to which the negative forces of a high population growth and increasing food prices have worsened its incidence. In the case of the determinants of agricultural productivity, the results show that accompanied with the size of the cropped area, fertiliser off-take has played the most significant and powerful role in increasing agricultural productivity through time in Pakistan, especially at the onset of the Green Revolution _ the introduction of High Yield Variety crops and seeds in the late sixties.
\end{abstract}

\section{Introduction}

\section{I.I Agriculture and Poverty in Pakistan - A Brief Overview:}

The urgency of development and poverty alleviation in Pakistan has resulted in the inevitable dilemma of whether or not industrial growth should take precedence over agricultural development. It is now widely held by development economists ${ }^{1}$ that industrialisation cannot achieve the goal of prosperity without the simultaneous transformation of the agricultural sector - the source of sustenance of the bulk of the nation's people. Therefore, in the presence of an ever increasing population a rise in agricultural/food productivity is imperative to support the growing needs of the people. Even though the last decade has seen a concentration of development in the urban manufacturing sector, Pakistan is still essentially an agricultural economy. Agriculture today contributes about 24 per cent of gross domestic product, accounts for half of the employed labour force and is the largest source of foreign exchange earnings. Unfortunately, since the inception of the country this sector has been severely mismanaged by both the government planning authorities and owner inefficiencies, not to

\footnotetext{
${ }^{1}$ Southworth \& Johnston. Page 10.
} 
mention the negative effects of the high degree of corruption prevailing in the system at large.

In spite of the fact that Pakistan has the largest single contiguous gravity flow irrigation system in the world, and from once being a granary of the sub-continent, it has become chronically deficient in food grains such as oil seeds, pulses etc. Instead of striving towards self sufficiency in the production of food - major cash crops, the country's import bill of wheat and edible oil alone has soared to Rs.60.0 billion per annum ${ }^{2}$ - a heavy drain on the national exchequer. A fitting example of the degree of inefficiency and misallocation within the agricultural sector is the indiscreet setting up of sugar mills and plantation of sugar cane in prime cotton and rice areas. This has resulted in a significant decline in the area and productivity of these crops, which happen to be the country's main export crops. All these deficiencies in the agricultural sector have had an adverse effect on the general economic health of the country, which cannot be better reflected than from the persistent high degree of poverty levels existing in the rural areas $(31$ per cent of the rural population in 1994 below subsistence) $)^{3}$.

\section{Review of Literature}

\subsection{Summary of Analysis of Selected Literature}

One of the most prominent papers on the subject of poverty and agricultural productivity is Ahluwalia $(1978)^{4}$. In this paper, Ahiuwalia specified the following model to examine the impact of agriculture performance on rural poverty:

$$
\operatorname{Pov}_{t}=c_{o}+{ }_{c 1} \operatorname{NDPARP}_{t}+{ }_{c 2} \mathrm{~T}
$$

Where "Pov" represents an index of rural poverty, NDPARP stands for net domestic product in agriculture per rural person and $\mathrm{T}$ is for time. This particular model was tested on all-India data spanning the period 1956-57 to 1973-74. Ahiuwalia employed three alternative measures of poverty in his analysis. For the explanatory variable NDPARP, two year values. A sample of the results is shown below:

\footnotetext{
${ }^{2}$ Pakistan Economic Survey 1996-97.

${ }^{3}$ Trends in Developing Economies, 1994, Page 395.

${ }^{4}$ Ahluwalia, M.S., 1978
} 
Table-1

\begin{tabular}{|c|c|c|}
\hline $\operatorname{PovI}_{t}$ & $\begin{array}{ccc}136.12 & -\mathrm{O} .55 \mathrm{NDPARP}_{\mathrm{t}}- & 0.141 \mathrm{~T}, \\
\left(\begin{array}{l}484) \\
(-3\end{array}\right) & (-0.64)\end{array}$ & $\mathrm{R}^{2}=0.50$ \\
\hline PovII $_{t}$ & $\begin{array}{l}=127.24-0.451 \mathrm{NDPARP}_{\mathrm{t}}-0.021 \mathrm{~T} \\
(580) \\
(3.64)\end{array}$ & $\mathrm{R}^{2}=0.62$ \\
\hline PovIII $_{t}$ & 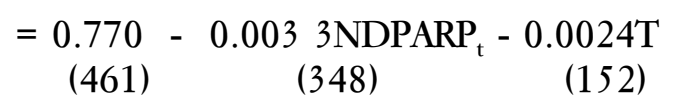 & $\mathrm{R}^{2}=0.52$ \\
\hline
\end{tabular}

From the above results, Ahiuwalia inferred that rural poverty is inversely related to the measure of agricultural productivity NDPARP and there is no residual time trend in poverty after allowing for changes in NDPARP. According to Ahiuwalia the above results suggest that there exists a certain amount of trickling down of benefits from increases in agricultural productivity.

G.M. Desai in "Trends in Rural Poverty in India: An interpretation of Dharm Narain", has given a reconstructed version of Dharm Narain's ${ }^{6}$ model which is essentially a modification of Ahtuwalia's model. This has been done through the inclusion of nominal prices of commodities consumed by the rural households as an exogenous variable along with agricultural productivity. The price variable has been specified in two alternative ways, the consumer price index for agricultural labourers (CPIAL) and the index number of wholesale prices of food grains (FPI). The following two models were hence formulated after logarithmic transformation of the variables.

$$
\begin{gathered}
\log \operatorname{Pov}_{t}=a_{o},+a l^{\prime} \log \operatorname{NDPARP}_{t}+a 2 \log \text { CPIAL }_{t},+a 3^{\prime} \log \mathrm{T} \\
\log \operatorname{Pov}_{t}=a_{o},+a 1^{\prime} \log \operatorname{NDPARP}_{t}+a 2 \log \mathrm{EPI}_{t},+a 3^{\prime} \log \mathrm{T}
\end{gathered}
$$

The above models were tested for a period ranging from 1956-57 to 1970-71, and the following estimated equations were obtained:

\begin{tabular}{|c|c|c|}
\hline $\begin{array}{r}\log \operatorname{Pov}_{\mathrm{t}}=4.592-0.631 \log \mathrm{NDP} \\
(-3.595)\end{array}$ & $\begin{array}{lr}.582 \log \text { CPIAL }_{t} ;- & 0.174 \log \mathrm{T} \\
(8.537) & (-5.595)\end{array}$ & $\mathrm{R}^{2}=0.93$ \\
\hline $\begin{array}{r}\log \mathrm{Pov}_{\mathrm{t}}=6.072-0.841 \log \mathrm{NDP} \\
(-4.837)\end{array}$ & $\begin{array}{l}0.499 \log \mathrm{FPI}_{\mathrm{t}},- \\
(8.022) \\
(-7.025 \log \mathrm{T}\end{array}$ & $\mathrm{R}^{2}=0.91$ \\
\hline
\end{tabular}

Table-2

\footnotetext{
${ }^{5}$ Desai.G.M.. 1985

${ }^{6}$ Pioneerins researcher in this field.
} 
In both the estimates NDPARP, the agricultural productivity variable, has a negative significant coefficient, corresponding to the findings of Ahiuwalia. The price variables have a positive coefficient, signifying the indirect effect of a rise in agricultural production on the alleviation of poverty through a reduction of good prices during the period of the Green Revolution in India. The negative time trend indicates a reduction in poverty through time due to exogenous variables which have not been included in the model.

Development economist Ashwani Saith has ascribed the negative time trend to the increased rural-urban migration which according to his study, might have reduced the impact of rural poverty in India during this particular period of time ${ }^{7}$. Saith, estimated a model similar to that of Narain's over the same time period, but took the percentage deviations of the index of both agricultural productivity and price index of agricultural labourers from their fitted trend values as the explanatory variables. His results shown below indicate that price rises accentuate poverty more than increased agricultural production alleviates it.

Table 3

\begin{tabular}{|c|c|}
\hline $\operatorname{Pov}_{t}=43.08-0.28$ DIAP $_{t}+0.32$ DCPIAL $_{t},+0.64 \mathrm{~T}$, & $\mathrm{R}^{2}=0.93$ \\
\hline
\end{tabular}

\subsection{Literature on the Determination of Agricultural Productivity}

The first paper reviewed in this section deals with the greater efficiency in production generated through the education of the farmer in the case of the cultivation of High Yield Variety crops (HYV) which represent the introduction of new technology in the wake of the Green Revolution in Pakistan. The author of this paper, Rauf A. Azhar ${ }^{8}$ hypothesises that in the case of the new HYV crop varieties, the difference in the farmers' educational background has a significantly greater effect on the technical efficiency of production, than compared to the traditional crop type. In other words, education coupled with new technology results in greater production, than education combined with traditional methods of production. For each of the crop varieties a modified Cobb-Douglas production function is estimated, using cross sectional farm data for 197677, from a WAPDA ${ }^{9}$ survey. The reason behind taking this particular period is the widespread adoption of the HYV varieties in the late 70s in Pakistan.

\footnotetext{
${ }^{7}$ Saith,Ashwani.,1981.

${ }^{8}$ Azhar, Rauf A., 1985.

${ }^{9}$ Water and Power Development Authority of Pakistan.
} 
The modification on the usual Cobb-Douglas function done by Azhar is through the introduction of shift variables, which are inputs other than land and labour which are non-essential and can obtain a zero value The estimated equation is the following:

$$
\text { Iny }=C+a_{0} \operatorname{InN}+a_{1} I n l+\beta_{1} r+\beta_{2} n+\beta_{3} P+\beta_{4} m+\beta_{5} s .
$$

When:

$$
\begin{aligned}
& \mathrm{Y}=\text { farm crop output (maunds) } \\
& \mathrm{N}=\text { farm crop area (acres) } \\
& \mathrm{I}=\text { Labour unit (man days/acre) } \\
& \mathrm{r}=\text { irrigations (number of water applications/acre) } \\
& \mathrm{n}=\text { nitrogenous fertiliser ( } \mathrm{kg} / \mathrm{acre}) \\
& \mathrm{p}=\text { phosphorous fertiliser ( } \mathrm{kg} / \mathrm{acre}) \\
& \mathrm{m}=\text { farmyard manure (maunds/acre) } \\
& \mathrm{s}=\text { years of schooling of the farmer. }
\end{aligned}
$$

The following are a sample of the results, with wheat crop output (HYV and traditional), as the dependent variable after using Ordinary Least Squares (OLS) methodology:

\section{Table 4}

Wheat (HYV): $\operatorname{In} Y=2.03+0.875 \ln N+0.0081 \ln l+0.093 r+8.31 \mathrm{E}-04 n+0.0015 p+$
$5.89 \mathrm{E}-04 m+0.0128 s$
$\mathrm{R}^{2}=0.604$
(17.99)
$(31.880)$
$(0.400)$
(10.887)
$(2.818)$

Wheat (traditional):

$\operatorname{Ln} Y=1.58+0.948 \ln N+0.0251 \ln l+0.103 r 6.75 \mathrm{E}-05 n+8.22 \mathrm{E}-04 p+$ $3.76 \mathrm{E}-05 m+0.0077 s$ $\mathrm{R}^{2}=0.573$

$\begin{array}{llllllll}(5.76) & (13.721) & (0.436) & (4.494) & (0.061) & (0.158) & (0.036) & (0.356)\end{array}$

The above results according to Azhar, show that education in the case of the HYV variety has a positive significant effect on production as compared to the traditional variety for which education is insignificant, hence corroborating the main hypothesis. Moreover, the results also show 
that HYV variety is more efficiently employed by small farmers as indicated by the lower coefficient of elasticity of cropped area for the HYV estimates. Also, the labour coefficient in both cases are positive and insignificant, while the elasticity coefficients of fertilisers and manure are positive and significant only for the HYV variety crop. Azhar maintains that the latter results show that the effect on production of new technology during the Green Revolution was stimulated primarily by fertiliser off-take.

The second study reviewed here deals with the estimation of technical efficiency in agricultural production in the North West Frontier Province of Pakistan. This study carried out by A. Parikh and K. Shah ${ }^{10}$ measures technical efficiency using a translog frontier production function on cross sectional data from 397 farms in the area, for the year 1988-89. Through the estimation of the following translog function and applying the Stochastic Production function ${ }^{11}$ the authors have constructed an efficiency index, which is than employed as the endogenous variable to get the determinant of technical efficiency.

Translog function: $\log y=\beta o+\sum_{t-1}^{5} \beta i \log \mathrm{x}_{\mathrm{i}}+\mathrm{I} / 2 \sum \sum \gamma_{\mathrm{ij}} \log \mathrm{x}_{\mathrm{i}} \log \mathrm{x}_{\mathrm{i}}+\epsilon$

Where $\mathrm{y}$ and $\mathrm{x}$ are output and input per acre respectively. Where the inputs $\left(\mathrm{x}_{\mathrm{i}}\right.$ 's) are the costs per acre of manure, fertiliser, wage, bullock and tractor. The only variable found to be significant after using the Maximum Likelihood estimation method was fertiliser with a marginal productivity of 0.38 . The index of efficiency obtained by applying the stochastic production function approach yielded a high level of efficiency on an average (mean level 96.2 per cent), suggesting the well-developed infrastructure of the region and the usage of advanced inputs e.g. HYV, irrigation and chemical fertilisers for many years. The next step by the authors was to identify the determinants of technical efficiency. This was done through the OLS estimation of the following model:

$$
T E,=a+\beta_{1} F S_{1}+\beta_{1} F S_{1}+\beta_{2} A G_{1}+\beta_{3} E D_{1}+\beta_{4} O E_{1}+\beta_{5} A S_{1}+\beta_{6} W T_{1}+\beta_{7} C D_{1}+\beta_{8} F G i+\beta_{9} E X_{1}+\mathrm{V}_{1}
$$

The above variables of the model are, in order, technical efficiency (TE), family size (FS), age of the head of household (AG), education of the

\footnotetext{
${ }^{10}$ Parikh, A. \& Shah, K 1994.

${ }^{11}$ Stochastic Prod. Function: $\mathrm{y}=\mathrm{f}(\mathrm{xi}, \mathrm{b}) \mathrm{e}^{\epsilon}$ where $\in=u+\mathrm{v}$. Measure of Technical efficiency for each farm: $\mathrm{TE}=\exp [\mathrm{E}\{\mathrm{u} / \in\}]$ where $\mathrm{E}(\mathrm{u} / \in)=\sigma_{\mathrm{u}} \sigma_{\mathrm{v}} / \sigma\left[\mathrm{f}(\in \lambda / \sigma) / 1-f(\in \lambda / \sigma]\right.$ and $=\sigma_{\mathrm{u}} / \sigma_{\mathrm{v}}$
} 
head (ED), off-farm work (OE), value of farm assets per acre (AS), value of non-farm assets per acre (WT), credit per acre (CD), degree of fragmentation (FG) and meetings with extension service (EX). The results of the above model indicated that family size (due to shortage of labour in the area), education and credit per acre increase farm efficiency while fragmented land decreases it significantly.

\section{Empirical Analysis}

\subsection{Theoretical Foundation to the Model}

\subsubsection{An Overview}

The theoretical analysis of agricultural productivity and its effect on poverty in a dynamic framework (changes through time in a traditional society and the transformation to a progressive society) divulged certain variables which provide the linkage effects between poverty and productivity. These variables were essentially agricultural population, labour force and the price levels. Rapid population growth intuitively worsens poverty, by quickly exhausting both the land and existing income sources, while increase in the labour force or employment through enhanced productivity in rural areas lessens its incidence. If prices received by farmers is considered, then increases in it benefit the farmer and the effects can also trickle down to the landless labourer through higher wages and increased employment. On the other hand a rise in prices paid would have an adverse effect on the landless labourers by forcing down their real incomes possibly below subsistence level. Therefore the effect of productivity on poverty through prices is mainly an issue of the degree to which agricultural productivity affects prices and the specification of the price variable. The following section deals with the empirical investigation of the effect agricultural productivity, prices and population have had on poverty levels in Pakistan.

\subsubsection{Agricultural Productivity, Prices, Employment and Poverty: All Pakistan Analysis}

Based on the theory and the past empirical work on this subject the following two models, with two separate agricultural commodity price variables, have been specified to test the relationship between agricultural productivity and poverty.

$\log \mathrm{POV}_{\mathrm{t}}=\alpha_{\mathrm{o}}+\alpha_{1} \log \mathrm{IAGR}_{\mathrm{t}}+\alpha_{2} \log \mathrm{ASPI}_{\mathrm{t}}+\alpha_{3} \log \mathrm{POP}_{\mathrm{t}}+\alpha_{4} \log \mathrm{TIME}+\mathrm{u}_{\mathrm{t}}$. 


$$
\log \mathrm{POV}_{\mathrm{t}}=\alpha_{\mathrm{o}}+\alpha_{1} \log \mathrm{IAGR}_{\mathrm{t}}+\alpha_{2} \log \mathrm{ASPI}_{\mathrm{t}}+\alpha_{3} \log \mathrm{TIME}+\mathrm{u}_{\mathrm{t}}
$$

where $^{12}$

POV $_{\mathrm{t}}$ Head count index (Average Poverty line: Exp. 100-109 Rs./cap/rnonth in 1979 prices and subsequent changes in accordance with World Bank Report 1990 on average rural poverty reductions in Pakistan). ${ }^{13}$

IAGR $_{\mathrm{t}}$ Index of Agricultural Production. ${ }^{14}$

ASPI $_{t}$ Procurement/Support Price Index of Agricultural Commodities. (Rs/40Kg.) $)^{15}$

ACPI $_{t}$ Agriculture Consumer Price Index. ${ }^{16}$

POP $_{t}$ Rural Population. (Millions) $)^{17}$

The hypothesis to be tested or the expected sign of coefficients as postulated by the theory for both the models above are the following:

- $\alpha_{1}($ IAGRP $)<0$

- $\alpha_{2}$ (ASPI) $<0, \alpha_{2}$ ACPI $>0$

- $\alpha_{3}$ POP . 0

- $\alpha_{4}$ TIME $>0$ or $<0$

In other words, the central hypothesis to be tested here is that agricultural productivity not only increases the revenues of the land holding class, but also increases the real incomes and employment levels of the landless labourers, in short it reduces the incidence of rural poverty. The above two models were tested for the period 1970 to 1996 and 1973 to 1993 respectively on the all Pakistan data described above. The following are the estimated equations obtained through Ordinary Least Squares regression procedure:

\footnotetext{
12 The data on agricultural productivity, prices and population was obtained from Pakistan as it was not available in the UK.

${ }^{13}$ Sources: "The incidence of poverty in developing countries: An ILO Compendium of data. 1992" pages 34-35 \& World Development Report, 1990 (And relevant years)

${ }^{14}$ Source: Economic Survey of Pakistan 1996-97.

${ }^{15}$ Ibid.

${ }^{16}$ Source: World Tables 1995. IBRD Publ.

${ }^{17}$ Source: Economic Survey of Pakistan, 1996-97.
} 
Table-5 : Agricultural Productivity and Poverty

\section{Model I}

(1) Estimate with Agricultural Procurement/Support price (ASPI)

$$
\begin{aligned}
& \log \mathrm{POV}_{t}=-2.86-0.18 \log \mathrm{IAGR}_{\mathrm{t}}+0.50 \log \mathrm{ASP}_{\mathrm{t}}+1.54 \log \mathrm{POP}_{\mathrm{t}}-2.06 \log \mathrm{TIME} \\
& \begin{array}{rrrrr}
-2.224 & -2.248 & 2.8176 & 3.8871 & -6.344 \\
(* * *) & (* * *) & \left(* * * \mathrm{~S}^{*}\right) & (* * *) & (* * * *)
\end{array} \\
& (* * *) \quad(* * *) \quad\left(* * * S^{*}\right) \quad(* * * *) \quad(* * * *) \\
& \mathrm{R}^{2}=0.87 \quad \text { F-stat }=36.26 \quad \text { D.W }=-1.80
\end{aligned}
$$

Model 2

(2) Estimate with Agricultural Consumer Price Index $\mathrm{ACPI}_{\mathbf{t}}$ )

$$
\begin{array}{rrrr}
\log \mathrm{POV}_{\mathbf{t}}=-2.32-0.02 \log \mathrm{IAGR}_{\mathbf{t}}+0.52 \log \mathrm{ACPI}_{\mathbf{t}}-0.47 \log \text { TIME } \\
-2 \text { 266 } & -0.225 & 2.316 & -3.531 \\
(* * *) & (* * *) & (* * * *) \\
\mathrm{R}^{2}=0.67 & \text { F-stat }=11.88 & \text { D.W }=-1.76
\end{array}
$$

Model 2 Modified

(3) Estimate with lagged Agricultural Productivity

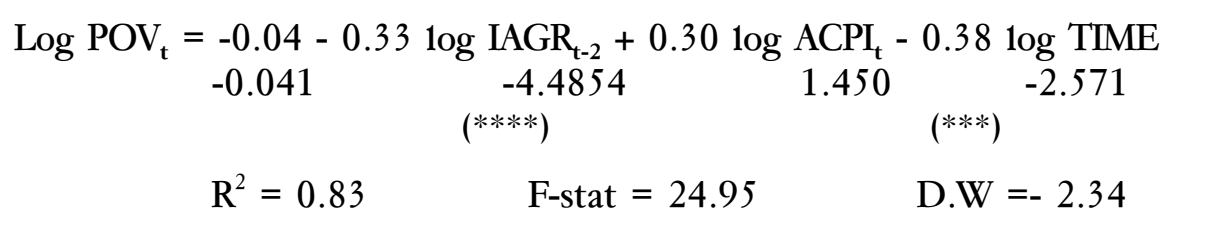

Note $(* * * *)$ indicates significance at the $1 \%$ level.

$(* * *)$ indicates significance at the $5 \%$ level.

The above results indicate that all the explanatory variables have a significant effect on poverty in the first equation. In the estimate of the first equation the central variable, agricultural productivity, is significant at the 5 per cent level, with a negative coefficient $(-0.18)$, according to which an increase of 0.18 units in the agricultural productivity index results in a 1 per cent decline in the poverty index. Hence the central hypothesis that agricultural productivity reduces rural poverty is accepted. In the second estimate agricultural productivity is insignificant, while in the third it becomes significant with a negative coefficient $(-0.34)$, almost twice more powerful than in the first estimate, after it is lagged far two years to provide a cushioning effect. ${ }^{18}$

\footnotetext{
${ }^{18} \mathrm{~A}$ fall in productivity might not affect poverty levels immediately as the rural poor resort to the selling of assets etc. to meet subsistence requirements at least for a short period of time.
} 
The above results suggest that the trickle down effect of increased agriculture productivity has been present to a certain degree during the past couple of decades in Pakistan. Though it was argued in the theoretical analysis that in the presence of large disparities in land ownership, increased productivity can result in greater inequalities as the benefits of it are biased towards the land owners, the results show that productivity increases have benefited the subsistence farmers and the landless labourers also. These benefits are essentially through the direct effects of productivity increase which, as mentioned in the theory section, are increased wages a employment. Though the analysis on the effects of agricultural productivity on labour wages could not be carried out due to data problems, the following model was estimated over a period ranging from 1970 to 1996, to see the effect agricultural productivity has had on rural employment:

$$
\operatorname{lngLAB}{ }_{t}=\alpha_{o}+\alpha_{1} \log \text { POP }_{t}+\alpha_{2} \log \mathrm{ACRP}_{t}+\alpha_{3} \log \mathrm{ASPI}+\mathrm{u}_{\mathrm{t}}
$$

Where:

$\mathrm{LAB}_{\mathrm{t}}$.Agricultural Labour Force (Millions) ${ }^{19}$

Table6: Agricultural Productivity and Rural Employment

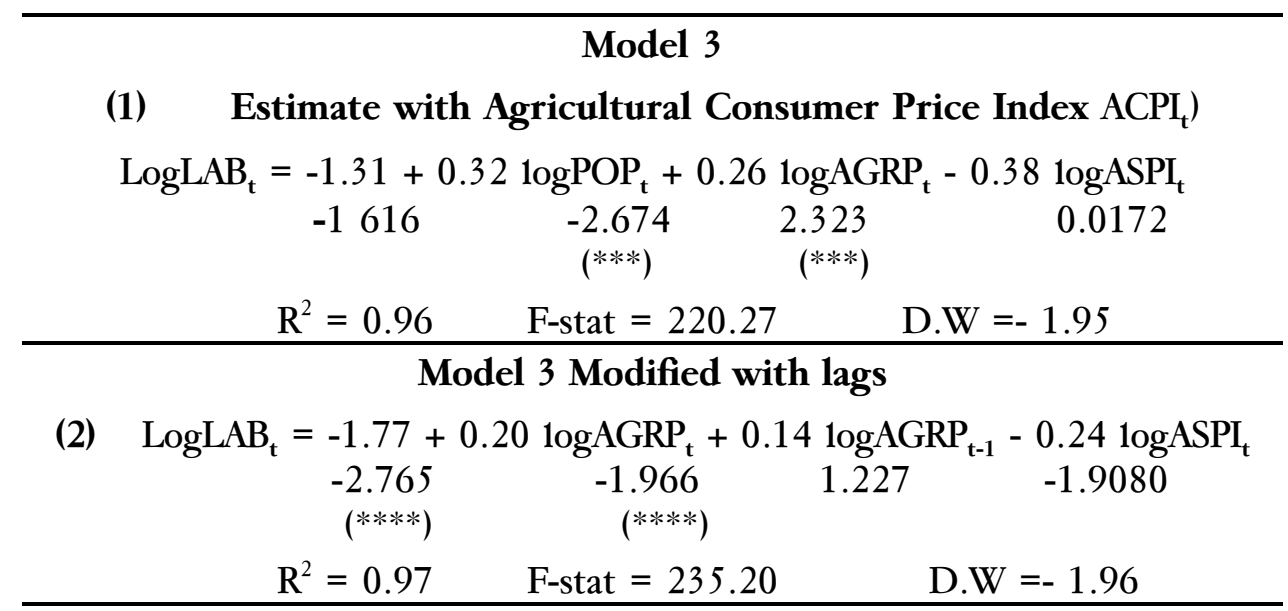

Note $(* * * *)$ indicates significance at the $1 \%$ level.

$(* * *)$ indicates significance at the $5 \%$ level.

The above results, of both the estimates, indicate the presence of positive trickle down effects of an increase in agricultural productivity. According to the results, increased agricultural productivity has had a significant positive effect on the agricultural labour force or employment level in Pakistan in the past couple of decades. Therefore, productivity

\footnotetext{
${ }^{19}$ Source: Economic Survey of Pakistan, 1996-97.
} 
increases have not been characterised completely through the displacement of labour with mechanisation, and the positive effects on employment have filtered down to the poor and reduced poverty levels. In addition to this it has to be noted that population growth, as seen in the estimates, has a significant and a bigger impact on growth $(0.32$ and $0.2-1)$ of the rural labour force than the absorption capacity of the agricultural sector $(0.26$ and 0.20 ). Therefore, there is a constant pressure on the agricultural sector to absorb the growing surplus labour, which if not employed would not only worsen the existing rural poverty levels but would also dampen the productivity of the urban manufacturing sector due to continued migration. According to a recent, study, the percentage of rural immigrants living in unserviced areas of cities was about 2) percent in the mid-1980s and is expected to rise to 60 per cent by the end of the century in Pakistan. ${ }^{20}$

Referring to Table I, the procurement/support price variable in the first equation is significant and has a high positive coefficient $(0.50)$ as opposed to the negative coefficient postulated by theory. This reflects the fact that even though the government of Pakistan has been providing farmers with price supports ${ }^{21}$ to check the fluctuations in agricultural commodity prices, the large landless and subsistence farming class has been severely affected by the increasing food price trend, which is somewhat reflected in the support or procurement prices. The second estimated model with agricultural consumer price index as an explanatory variable confirms the detrimental effect prices have had on rural poverty in Pakistan. The variable is significant and has a positive coefficient of 0.52 as hypothesised. Thus in both the estimates, price has a much more powerful adverse impact on poverty than agricultural productivity has in its alleviation.

In the theoretical analysis, the indirect effects of agricultural productivity were mainly attributed to the change in food prices. Higher productivity is supposed to reduce the prices of agricultural commodities hence increasing the area of the entitlement mapping of the poor subsistence farmer and landless labourer. This results in the reduction in poverty levels through the increase in the real incomes of the poor. In order to empirically investigate the degree of the indirect effect of higher agricultural productivity on poverty through food prices, the following model was estimated:

$\log \mathrm{ACPI}_{t}=\alpha_{\mathrm{o}}+\alpha_{1} \log \mathrm{AGRP} \mathrm{P}_{\mathrm{t}}+\alpha_{2} \log \mathrm{AGRP} \mathrm{t}_{\mathrm{t}-1}+\alpha_{4} \log \mathrm{APOP}+\alpha_{2} \log \mathrm{TIME}+\mathrm{u}_{\mathrm{t}}$

\footnotetext{
${ }^{20}$ Hussain, Akmal, page 4.

${ }^{21}$ The support price acts as a minimum guaranteed price for growers, and safeguards their interest if the open market prices tend to fall during the post harvest season.
} 
Table 7: Agricultural Productivity and Food Prices

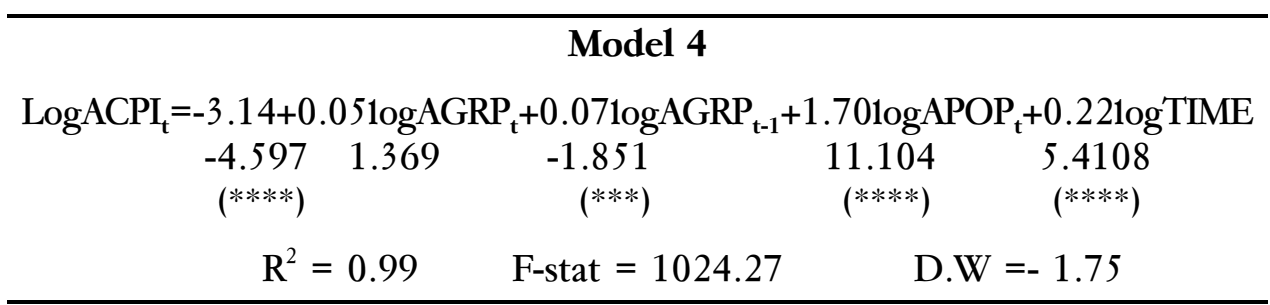

Note $(* * * *)$ indicates significance at the $1 \%$ level.

$(* * *)$ indicates significance at the $5 \%$ level.

In the above model, the lagged agricultural productivity variable has been included to capture the latent effects of fluctuations of productivity or price levels. ${ }^{22}$ The results indicate that increases in agricultural productivity lower food prices with a time lag of one year. The coefficient of productivity in relation to prices is quite low (0.07), especially if it is compared to the population coefficient (1.7). The results corroborate the theory to a large extent. There is a trickling down of benefits through the price variable, but due to the much bigger impact of population growth on prices (demand pull inflation) these positive effects are more or less neutralised. Moreover food price increases in the case of Pakistan in the past couple of decades have not only been characterised by demand pull inflation, the increasing input costs of modernising the methods of production e.g. use of fertiliser, pesticide, renting tractors etc. has also resulted in cost push inflationary pressures on food prices. ${ }^{23}$ Furthermore, in the past couple of years there have been serious shortages in food supply due to low cotton, sugar cane and wheat production which has pushed up food prices considerably. ${ }^{24}$ These inflationary effects are extremely detrimental to the rural landless labourer, as the results of Table I show prices to be much more powerful than mere productivity in affecting poverty.

Referring to Table 1, population, as postulated by theory, has a highly significant positive coefficient (1.54), and thus has played a leading role in increasing the incidence of rural poverty in Pakistan. Furthermore, in the analysis of the indirect effects of agricultural production, with population in the back drop, the estimated models in both Tables 2 and 3 strongly suggest that population counters all the indirect positive effects of production increase. It not only raises the price levels through time but also

${ }^{22}$ Formulation based on Raghav Gaiha's model in Poverty, agricultural production and prices in rural India - a reformulation. Page 346

${ }^{23}$ Economic Survey of Pakistan. 1996-97 page 9.

${ }^{24}$ Ibid., page 15 . 
puts employment pressures on both the rural and the urban sector, hence leading to greater poverty. In the past three decades the growth of population in Pakistan has been on an average 3 per cent per annum while agricultural growth has been stagnant at a growth rate of 4 per cent per year during this time. ${ }^{25}$

Lastly, the negative significant coefficient of the time variable in all three estimates in Table-1 suggests that poverty has also been reduced by other factors not included in the model. This is in conformity with the findings of Ashwani Saith ${ }^{26}$, who has ascribed the negative time trend to the increased rural - urban migration in developing countries, which to a certain extent has mitigated the impact of rural poverty. In Pakistan the rural labour force has declined by 16 per cent in the past three decades due to increased migration to urban areas though agriculture will remain the largest source of employment in the country. ${ }^{27}$

\subsection{Determinants of Agricultural Productivity in Pakistan}

\subsubsection{The Model}

For the purpose of analysing agricultural production through the course of time, the following dynamic Cobb-Douglas production function, presented in detail in the theory section, is employed for the estimation of the agricultural production function:

$$
\gamma(t)=N(t)^{\mathrm{b} 1} L(t)^{\mathrm{b} 2} \sum_{i=1}^{n} K_{I}(t)^{b i}
$$

Where $\mathrm{Y}(\mathrm{t})$ represents total production, $\mathrm{N}(\mathrm{t})$ is the cropped area, $\mathrm{L}(\mathrm{t})$ is the labour force and $\mathrm{K}(\mathrm{t})$ stands for the capital inputs. The implicit assumption in the estimation procedure of the above model is that the level of technology in Pakistan improved significantly in the late $60 \mathrm{~s}$ in the wake of the Green Revolution, but has since then remained fairly constant, though the combination and degree of intensity of inputs has changed through time. This assumption allows us to estimate a time series production function, which in the scenario of constantly changing technology can only be employed for a time period representing a specific state of technology After simplification the following model is obtained:

$$
\Delta \mathrm{Y} / \mathrm{Y}=\mathrm{b}_{1} \Delta \mathrm{N} / \mathrm{N}=\mathrm{b}_{2} \Delta \mathrm{L} / \mathrm{L}+\sum_{i=1}^{n} \text { bi } \Delta\left(\mathrm{K}_{\mathrm{i}} / \mathrm{K}_{\mathrm{i}}\right)
$$

\footnotetext{
${ }^{25}$ Ibid., page 15-16.

${ }^{26}$ Saith, Ashwani., 1981.

${ }^{27}$ Economic Survey of Pakistan. 1996-97. Page 22.
} 
By simply denoting $\Delta \mathrm{Y}=\Delta \mathrm{N} / \mathrm{N}$ and so on, the model to be tested is:

$\Delta \mathbf{Y}=\mathbf{b}_{\mathbf{o}}+\mathbf{b}_{\mathbf{i}} \Delta \mathbf{N}+\mathbf{B}_{2} \Delta \mathbf{L}+\mathbf{B}_{3} \Delta \mathbf{K}_{\text {Fert. }}+\mathbf{B}_{4} \Delta \mathbf{K}_{\text {Trac. }}+\mathbf{b}_{5} \Delta \mathbf{K}_{\text {Irrig }}+\mathbf{b}_{6} \Delta \mathrm{K}_{\text {Cred. }}+\mathbf{u}_{\mathrm{t}}$

Where: ${ }^{28}$

Y Total Food Grains (tonnes)

N Total Cropped Area (million hectares)

L Labour Force (million)

$\mathrm{K}_{\text {fert }} \quad$ Fertiliser off-take (000 N/tonnes)

$\mathrm{K}_{\text {trac }} \quad$ Area irrigated by all sources (million hectares)

$\mathrm{Y}_{\text {irrig }} \quad$ Total Tractor Supply (nos)

$\mathrm{K}_{\text {cred }} \quad$ Total Credit Disbursed (Rs. million)

\subsubsection{The Determinants of Agricultural Production 1968-1996}

The results obtained through the Ordinary Least Squares regression procedure of the entire sample period 1968-1996 are shown in the table below:

Table 8: Estimation of Agricultural Production 1968-1996

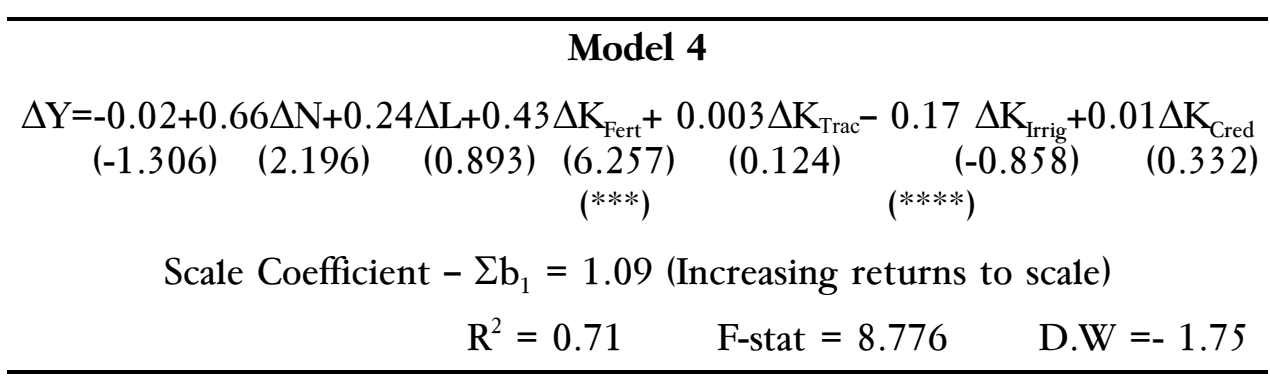

Note $(* * * *)$ indicates significance at the $1 \%$ level.

$(* * *)$ indicates significance at the $5 \%$ level.

The above estimation of the agricultural production function over the entire period 1968-96 indicates that there are only two inputs which have significantly affected the growth of production in Pakistan. Cropped area with an elasticity coefficient of 0.66 , is significant at the 5 per cent

${ }^{28}$ Source: Economic Survey of Pakistan. 1996-97. (For all variables listed below). 
leve1, while in the series of capital inputs fertiliser off take is significant at the I per cent level with a coefficient of elasticity of 0.43 . The scale coefficient of 1.09 shows that the sector has experienced at an aggregate, increasing returns to scale. In other words a I per cent increase in both fertiliser off take and cropped area results in a 1.09 per cent increase in total agricultural output. The insignificance of Labour is probably due to the presence of a large labour force in rural areas, which has a marginal productivity of near zero and therefore at a marginal level has an insignificant effect on total product. This reflects the theoretical foundation of the Arthur Lewis model of surplus labour, in which a zero marginal productivity of labour is assumed. In Figure I presented in the theory section, the production point of the agricultural sector of Pakistan can be associated with point $\mathrm{C}$, where the marginal productivity of labour is zero, but total product, given a particular state of technology, is at its maximum.

The other capital inputs namely tractors, irrigation and credit disbursed are insignificant in affecting aggregate agricultural productivity in Pakistan. In the case of tractors, only a small proportion of the farming community has access to them or can afford its costs of purchase and use. Government experts estimate that about 25 per cent of farmers still use traditional methods such as oxen and hand ploughs, about 55 per cent use a mix of traditional and modern methods and the remaining 20 per cent have adopted modern technology and equipment such as tractors. ${ }^{29}$ Therefore, as a consequence of the scant use of tractors it could not have played a significant role in productivity during the past three decades. The irrigation variable has been insignificant during this entire period due to the continued inefficiency and misallocation of the water resources in the country. In spite of the presence of the world's largest contiguous surface water distribution system with 36,000 miles of canal conveyance which irrigates 78 per cent, is water logged. ${ }^{30}$ Therefore, mismanagement of the irrigation system has literally resulted in a loss of crop productivity rather than any significant increase in it.

Lastly, the insignificance of the rural credit variable reflects the inefficient and highly inequitable distribution of agricultural loans. Even though the Agricultural Development Bank of Pakistan has now been in existence for thirty years, most of the credit distributed is directed towards the large landholding families exerting political influence. ${ }^{31}$ Foreign aid and loans targeted towards the small farmers fail to even reach their target

\footnotetext{
29 “'The state of goods and agriculture. 1996' F.A.O. Agriculture Series. 1996

${ }^{30}$ ibid.

${ }^{31}$ It should be noted that in rural areas there is a large informal sector, and, and most of credit obtained by small farmers is through the informal credit market which is not accounted for in official statistics.
} 
groups. According to the Swiss Development Corporation Mission, at most 5 to 15 per cent of the target group of small farmers benefit directly from development loans. ${ }^{32}$

At this stage the agriculture production function for the period of the Green Revolution and post-Green Revolution is estimated. The graph below clearly indicates the two time periods in agricultural productivity. The 1960-1980 (Green Revolution) is a period of fairly high growth, while the following years have seen a significant fall in productivity.

Table 9: Estimated during the Green Revolution 1968-1980

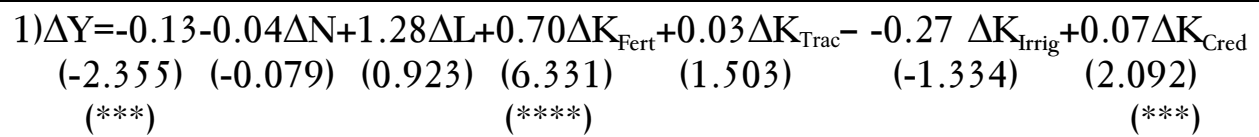

$$
\begin{aligned}
& \text { Scale Coefficient }-\Sigma \mathrm{b}_{1}=0.77 \text { (decreasing returns to scale) } \\
& \mathrm{R}^{2}=0.92 \quad \text { F-stat }=11.542 \quad \text { D.W }=-2.67 \\
& 2) \Delta \mathrm{Y}=-0.003+1.99 \Delta \mathrm{N}+0.59 \Delta \mathrm{L}+0.43 \Delta \mathrm{K}_{\text {Fert }}+0.04 \Delta \mathrm{K}_{\text {Trac }}--2.30 \Delta \mathrm{K}_{\text {Irrig }}+0.01 \Delta \mathrm{K}_{\text {Cred }} \\
& \begin{array}{llllll}
(-0.237) & (2.662) & (1.955) & (2.692) & (-0.909) & (-1.889)
\end{array} \\
& (* * *) \quad(* * * *) \\
& \mathrm{R}^{2}=0.61 \quad \text { F-stat }=2.654 \quad \text { D.W }=-2.02
\end{aligned}
$$

Note $(* * * *)$ indicates significance at the $1 \%$ level. $(* * *)$ indicates significance at the $5 \%$ level. $(* *)$ indicates significance at the $10 \%$ level.

The above results, in the case of the period of the Green Revolution, show that fertiliser off take is significant and has a very high coefficient of elasticity $(0.70)$. This indicates the fact that coupled with the new high yield variety crops and seeds, new technology such as fertilisers was very effective in terms of their marginal productivities. The second variable which is significant is the credit disbursed, with an elasticity coefficient of 0.07. As mentioned before, the Agricultural Development Bank of Pakistan was established in 1961, with the central aim to incorporate and facilitate the wide spread change in the method of "production in order to increase the efficiency and productivity of the agricultural sector. This was achieved during the period of the Green Revolution through the provision of easy credit to small farmers so that they could mechanise their farming techniques in step with the introduction of the high yield variety crops. This is the primary reason behind the

\footnotetext{
${ }^{32}$ Hussain, Akmal., page 24.
} 
significance of the credit variable, indicating that the provision of easy loans to small farmers did have a significant impact on overall agricultural productivity. The rest of the input variables are insignificant, the reasons behind their ineffectiveness have been outlined in the previous section with the exception of cropped area which in this case is insignificant, probably due to the lack of utilisation of cultivable area during this period of time. Overall, the returns to scale in the period of the Green Revolution are decreasing, reflecting the fact that the momentum of the new technology was not kept up and hence the potential benefits of the changes were never exploited fully.

The estimate for the post Green Revolution period reveals four inputs to be significant in the production process. Labour, which was insignificant in the past, is significant with a positive coefficient of elasticity (1.955). This is mainly due to the excessive rural-urban migration during the last' decade which, to a great extent, relieved the pressure of surplus unproductive labour from the rural areas of Pakistan. Statistics indicate that the share of labour employment in agriculture has dropped from a staggering 60 per cent in the 60 s to 46 per cent in the 80 s and $90 \mathrm{~s}^{33}$ The marginal productivity of fertilisers during this period has dropped to 2.69. This is due in the main to the unavailability of fertilisers to the small farmers, high costs, and adulteration of the product in domestic production, which has an adverse effect on production. ${ }^{34}$

Though cropped area in this period has a positive significant effect on productivity, the variable of irrigation has interestingly a negative significant elasticity coefficient (-2.30). This high coefficient, representing negative marginal contribution to productivity reflects the high degree of inefficiency and misallocation of the water resource in the country during the past two decades. According to the FAO report of 1996, the efficiency of the irrigation system in Pakistan has been given a rating of 35 per cent to 40 per cent. Water logging and salinity as mentioned before, are a major problem caused by the sub-optimal usage of water. These problems have claimed 35 per cent of the cultivable land in Pakistan. The credit variable is insignificant (the reasons behind this were mentioned in the last section) the central reason being the inequitable distribution of loans by government agencies.

In conclusion, it can be said that through the course of agricultural production in Pakistan fertiliser is the only 'input which has consistently played a significant role especially during the time of the Green Revolution,

\footnotetext{
${ }^{33}$ Economic Survey of Pakistan, 1996-97, page 22.

34 “The state of goods and agriculture. 1996." FAO. Agriculture Series.
} 
when these were coupled with the HYV variety seeds. Moreover, due to the expense and inviolability of other forms of capital, the largest segment of the rural population - the subsistence farmer has not been able to transform the method of production significantly. This is indicated by the insignificant contribution to aggregate production of the otherwise productivity enhancing variables such as tractors. Finally, the government planning agencies have not utilised and distributed resources such as water and credit efficiently in the past three decades resulting in its lack of effectiveness in the production process.

\subsection{Policy Implications}

Though an entire array of policies aimed to alleviate poverty and enhance agricultural productivity can be listed, here we would restrict ourselves to only the most relevant. The first aim of the government of Pakistan should be to enhance the productivity of the agricultural sector through the provision of the required capital inputs which would speed up the transformation process. These inputs range from efficient provision of easy credit to the small farmer, availability of unadulterated fertiliser and pesticide, tractor and harvester services, improvement in the effectiveness of the vast irrigation system, utilisation of cultivable wastes and finally farmer education.

Furthermore, the high rate of population growth needs to be checked in order that the increased agricultural productivity has any significant effect on poverty. The prices of inputs in the production process have to be subsidised to reduce the ever increasing costs of cultivation, which inevitably push up food prices. In addition, the development of the non-agricultural mainly service sector of the rural areas is imperative in order to absorb the pressure of surplus labour. Lastly, the existence of the powerful informal sector with the big land/ holders exerting control over rural labour and the capital market has to be abolished in order for the transformation mechanism to have any effect in the first place.

The central problem in this research was the unavailability of data, this resulted in the aggregate estimation of models rather than province or regional based estimation. The effect of this is the inevitable generalisation of the results especially in the case of a country like Pakistan with a diverse agricultural sector with profound regional differences in both structure, soil quality-produce and techniques of farming. Therefore, any analysis on the effect of agricultural production on poverty should be either on a particular region over time or a cross-section of an area at a particular point in time. Moreover, the estimation of poverty level (Head Count Index) in this research does not directly indicate the inequalities in income resulting from 
increased agricultural production. Hence, a measure of inequality such as the Gini coefficient or an alternate measure of poverty such as the Sen Index for rural areas should be employed. Unfortunately data on the measures, for a reasonable time span is currently not available for Pakistain Lastly, the aggregate estimation of the dynamic production function has I problems as it tends to overlook the technological changes through the course of time and can lead to hybrid estimates of the actual production function. Therefore, for such an estimation cross-sectional data give more accurate results as it does not assume away implicit changes in technology. 
20 The Lahore Journal of Economics, Vol.3, No.1

\section{References}

Ahiuwalia, Montek S., "Rural Poverty and -agricultural Performance in India,” Journal ofDevelopment Studies, 14(3), 1978.

Azhar, Rauf A., "Education and Technical Efficiency during the Green Revolution in Pakistan," Economic Development and Cultural Change, Vo1. 43, 994-95.

Economic Survey of Pakistan, 1996-97. Government of Pakistan, Finance Division, Economic Adviser's Wing, Islamabad.

Hussain, Akmal., 1994. Poverty Alleviation in Pakistan, Lahore, Pakistan: Vanguard Books.

Mellor, John W. \& Desai, Gunvant M., 1985 (eds) Agricultural_Change and Rural Poverty. Variations on a Theme by Dharm Narain. Baltimore \& London: The John Hopkins University Press.

Parikh, A. \& Shah, K., "Measurement of Technical Efficiency in the North West Frontier Province of Pakistan." Journal of Agricultural Economics, 45(1), 1994.

Saith, A., "Production, Prices and Poverty in Rural India." Journal of Development Studies, 17(2), 1981.

Southworth, H. M. \& Johnston, B.F., 1967. Agricultural Development and Economic Growth, Ithaca \& London: Cornell University Press.

"The incidence of poverty in developing countries," An ILO Compendium of Data. ILO publication, 1995.

“Trends in Developing Economies”, World Bank, 1994. (Washington. D.C.).

World Tables., (4th ed. IBRD publication, 1987-1995).

World Development Report, 1990. World Bank Publication, Oxford University Press. 